\section{Propagation of Stewartia: Past Research Endeavors and Current Status}

\author{
Ajay Nair ${ }^{1,2}$ and Donglin Zhang
}

AdDITIONAL INDEX WORDs. rooting, overwintering, KIBA, stratification, semi-hardwood

Summary. Stewartias (Stewartia spp.) are prized for their camellia (Camellia japonica)-like flowers, intense fall color, and exfoliating bark. In spite of having outstanding ornamental value and features, these plants are not readily available for landscaping in the horticulture trade. The primary reason stated is the difficulty of its mass propagation and production. In the last two decades, considerable research has been conducted on various aspects of stewartia propagation such as seed germination, cutting type, light, rooting medium, rooting hormone, cold acclimation, and tissue culture. In this article, we discuss factors that directly influence propagation of stewartia and we highlight results of published studies to propagate stewartia. The evidence indicates success in adventitious rooting of cuttings but at the same time recognizes the continuing challenge associated with overwinter survival. Sexual propagation has also been studied, but its commercial application is limited. To date, there is lack of concrete information on why stewartia remains under-represented in our landscapes. It still remains unclear if it is the lack of consumer demand or existing propagation difficulties that is the cause of under utilization of stewartia. Given the information from most published studies, we suggest further research on the aspect of overwinter survival in addition to a survey of the nursery and greenhouse industry to accurately determine the cause behind the absence of stewartia in horticultural trade.

$\mathrm{T}$ There has been constant demand in the horticulture trade to produce plants that have unique features such as short stature, prolific summer growth, intense fall color, winterhardiness, etc. Stewartia, with its remarkable traits and features, qualifies to be in that category. Stewartia comprises of eight to 21 species, depending upon the author $(\mathrm{Li}$, 1996; Yang, 1997). Stewartias are distributed on both sides of the globe, mostly dwelling in the woodlands. Stewartia comprise both temperate (deciduous) and tropical species (evergreen). One of the most important stewartia species in the trade is japanese stewartia (Stewartia pseudocamellia), which was introduced into the United States in 1866 by Thomas Hogg, Jr. to a private greenhouse in New York (DeWolf, 1969). Stewartia grows well in U.S. Department of Agriculture hardiness zones 5 to 8 (Dirr, 1998). Most of the stewartias are small trees reaching 30 to $40 \mathrm{ft}$ in height and are easily distinguishable by their numerous creamy

Department of Plant, Soil, and Environmental Sciences, University of Maine, Orono, ME 04469

${ }^{1}$ Current address: Department of Horticulture, Michigan State University, East Lansing, MI 48824

${ }^{2}$ Corresponding author. E-mail: nairajay@msu.edu. white camellia-like flowers and smooth mottled bark (Hohn, 1994). The bark flakes in patches to reveal buff, tan, cinnamon, and plum colors during winter (DeWolf, 1969). With their beautiful and appealing flowers, magnificent exfoliating bark, spectacular fall colors, and low insect and disease problems, stewartias are an all season high-demand landscape tree (Spongberg and Fordham, 1975).

In spite of having such outstanding ornamental values and features, stewartia is not readily available for landscaping in the horticultural trade. The primary reason stated is the lack of efficient propagation techniques and the propagation challenges associated with stewartias (Struve and Lagrimini, 1999). Much work has been conducted to overcome propagation difficulties and to develop specific techniques, but the commercial availability of stewartia is still low. Researchers have, to a large extent, focused on various sexual and asexual propagation techniques to overcome the propagation problem. Various aspects of propagation such as seed scarification, cutting type, rooting hormone, rooting medium, nutrition, cold acclimation, and micropropagation have been specifically targeted and show promising results. Stewartia has been a plant of interest not only to the propagation experts, but also to taxonomists and molecular biologists. Researchers have conducted genetic linkage studies to track their center of origin and also to establish relationship between native and introduced species. With close to a dozen species and cultivars in different hardiness zones and appealing morphological characteristics, stewartia certainly has a remarkable potential of being a front yard ornamental tree. This article summarizes past research endeavors undertaken to propagate stewartias and also focuses on techniques and approaches to increase commercial availability.

\section{Seed propagation}

One of the fundamental problems associated with sexual (seed) propagation in stewartia is that it is a slow and unreliable process mainly because of complex dormancy mechanisms in the seed (Curtis et al., 1996). Irregular and infrequent seeding habit, low seed viability, and short longevity impede large-scale nursery production. Seeds of stewartia require certain warm and cold stratification treatments to germinate successfully. The standard nursery practice for production of stewartia seedlings is to sow seeds outdoors in the fall and to allow 2 years for seedling emergence. Under normal conditions, seeds that fall on the ground germinate not the following spring, but the one after (Hohn, 1994). To resolve this dormancy problem, experiments have been conducted on mechanical and chemical seed treatments to break seed dormancy and enhance germination percentages. Oleksak and Struve (1999) demonstrated that seed germination of japanese stewartia is

\begin{tabular}{llll}
\hline $\begin{array}{l}\text { Units } \\
\text { To convert U.S. to SI, } \\
\text { multiply by }\end{array}$ & U.S. unit & SI unit & $\begin{array}{l}\text { To convert SI to U.S., } \\
\text { multiply by }\end{array}$ \\
\hline 0.3048 & $\mathrm{ft}$ & $\mathrm{m}$ & 3.2808 \\
1 & $\mathrm{ppm}$ & $\mathrm{mg} \cdot \mathrm{L}^{-1}$ & 1 \\
$\left({ }^{\circ} \mathrm{F}-32\right) \div 1.8$ & ${ }^{\circ} \mathrm{F}$ & ${ }^{\circ} \mathrm{C}$ & $\left(1.8 \times{ }^{\circ} \mathrm{C}\right)+32$
\end{tabular}


promoted by desiccation avoidance, gibberellic acid $\left(\mathrm{GA}_{3}\right)$ treatment, and warm and cold stratification. If the seeds are exposed to ambient room temperatures for $48 \mathrm{~h}$ or $80^{\circ} \mathrm{C}$ drying conditions for $24 \mathrm{~h}$, they lose viability completely (Oleksak and Struve, 1999). The study also indicated that exposing seeds to a 24 -h aerated water soak in $1 \mathrm{mM} \mathrm{GA}_{3}$ and 3 months warm stratification $\left(25^{\circ} \mathrm{C}\right)$ followed by 7 months cold stratification $\left(4^{\circ} \mathrm{C}\right)$ significantly increased seed germination.

Final germination was $70 \%$ when seeds were given a 3 -d aerated water soak in $1 \mathrm{mM} \mathrm{GA}_{3}$ followed by 3 months warm, moist stratification $\left(25^{\circ} \mathrm{C}\right)$ and 4 months cold stratification $\left(7^{\circ} \mathrm{C}\right)$ (Struve et al., 1999). Germination in this case was not synchronous. Depending on the source of the mother plant, germination varied from $30 \%$ to $90 \%$ for seeds given a 3 -d aerated 1 mm $\mathrm{GA}_{3}$ soak followed by alternating warm stratification temperature $\left(20 / 12{ }^{\circ} \mathrm{C}\right.$ on an alternating 12 -h cycle for 3 months) before cold stratification for 10 months. Cold stratification alone for 9 months, without prior warm stratification, resulted in poor germination percentages (less than $1 \%$ ). The optimum temperature for warm moist stratification was $15{ }^{\circ} \mathrm{C}$.

Although success has been reported in breaking and overcoming dormancy of the seed (Oleksak and Struve, 1999; Struve et al., 1999), this technique has not been adopted by the industry. A drawback of seed propagation is that propagation of a specific cultivar is impossible when propagated by seeds. Asexual propagation is by far the most common and widely adopted method to propagate and maintain genetic integrity of ornamental plants in the nursery trade.

\section{Asexual propagation}

Asexual propagation by softwood and semihardwood cuttings is the most common technique in the nursery industry. However, successful cutting propagation of many woody plant taxa is limited by poor overwinter survival in the first propagation year (Smalley and Dirr, 1986). Low overwinter survival has been a significant problem in several important plants such as sugar maple [Acer saccharum (Donnelly and Yawney, 1972; Goodman and Stimart, 1987)], birch [Betula spp. (Flemer, 1982)], witchalder [Fothergilla spp. (Fordham,
1982)], azalea [Rhododendron spp. (Smalley and Dirr, 1986)], and japanese stewartia (Wilson and Struve, 2004). Stem cuttings of stewartia typically root well and develop healthy root systems in their first season, but are prone to die during the following winter or shortly after the onset of growth the following spring (Dirr and Heuser, 1987; Wilson and Struve, 2004). The symptoms associated with overwinter mortality are diverse. Cuttings put forth frail new growth that withers off and, ultimately, the cuttings die off (Waxman, 1965). In some cases, rooted cuttings fail to break bud after winter dormancy (Curtis et al., 1996).

Even though some success has been reported (Perkins and Bassuk, 1995), the overwinter survival problem of stewartia has been largely unresolved. To avoid this overwintering problem in tall stewartia (Stewartia monadelpha), Dirr and Heuser (1987) suggested layering as an alternative method. Hohn (1994) cited the possibility of grafting in stewartia, using tall stewartia and japanese stewartia as understocks. He further suggested that mountain camellia (Stewartia ovata) and chinese stewartia (Stewartia rostrata) can be successfully layered, but layering cannot become a commercial propagation protocol due to the limitation of low number of plants that could be produced.

Gouveia (1991) reported 80\% rooting in propagating korean stewartia, treating three noded cuttings taken between mid-June to mid-July with $2000 \mathrm{mg} \cdot \mathrm{L}^{-1}$ indolebutyric acid (IBA). However, there was no information provided in the article regarding the percentage of cuttings that were successfully overwintered. Struve and Lagrimini (1999) propagated japanese stewartia and overwintered them in large quantities. Unfortunately, once the cuttings were moved to outdoor conditions, only $17 \%$ of rooted cuttings survived. In the case of seedlings, the survival was reported to be $48 \%$ (Struve and Lagrimini, 1999). Therefore, overwintering is an important aspect for successful propagation of stewartia and other woody plants. There are a number of factors that are directly associated with overwintering of cuttings including: type and characteristic of cutting, wounding, rooting hormone, rooting medium, nitrogen fertilization, carbohydrate storage, cold acclimation, and overwinter storage temperature. The following sections will look into each of these aspects individually.

\section{Type and characteristic of cutting}

The type of cutting chosen for propagation significantly affects rooting and subsequent overwintering of cuttings (Hartmann et al., 2002). Softwood cuttings ensure higher chances of obtaining post-rooting growth, which will increase the production of photosynthates (Smalley et al., 1987). However, softwood is not always the preferred source of propagation, as softwood cuttings tend to wilt easily and need special care and attention (Hartmann et al., 2002).

Rooting ability and overwinter survival is influenced by the type of cutting in many genera such as camellia (Macdonald, 1974), sugar maple (Donnelly and Yawney, 1972), witchhazel [Hamamelis spp. (Dirr and Richards, 1989)], and oak [Quercus spp. (Drew et al., 1993)]. For mountain camellia, cuttings taken early in the season (softwood cuttings) are an excellent source of propagation (Curtis et al., 1996). Softwood and semihardwood stem cuttings of stewartia rooted when treated with 3000 to $8000 \mathrm{mg} \cdot \mathrm{L}^{-1}$ auxin solutions (Ekstrom and Ekstrom, 1988; Halward, 1966). Flemer (1982) listed the korean form of japanese stewartia as a species that could be successfully propagated from softwood cuttings. Late June to early July is the recommended period to collect stewartia cuttings for maximum rooting (Fordham, 1982). Gouveia (1991) reported that cuttings of korean stewartia (Stewartia koreana) taken in mid-June exhibit good rooting and establishment. Results from the study conducted in our laboratory have demonstrated that semihardwood cuttings of japanese stewartia, taken in July and treated with a combination of rooting hormones, produced satisfactory rooting percentages (Nair et al., 2008).

The source plant and the juvenility aspect of the cuttings is also an important factor to consider in cutting propagation. In terms of juvenility, the position of the cutting on the source significantly affects the subsequent rooting and overwinter survival. Ideally, cuttings should be taken from juvenile wood. In the case 
of japanese stewartia, it was demonstrated that rooting and survival rates were high for cuttings taken from the basal wound shoots when compared with canopy cuttings (Haynes, 1999). Attempts made in our laboratory to propagate japanese stewartia from hardwood cuttings were unsuccessful (Nair, 2006).

\section{Wounding and rooting hormone}

Root production in stem cuttings can be substantially increased by wounding the base of a cutting (Hartmann et al., 2002). Wounding increased root production in rhododendron, juniper (Juniperus spp.), maple (Acer spp.), and arborvitae (Thuja spp.) (Wells, 1962). Wounding is not only considered to speed up the rooting process, but also to improve the quality of roots produced (Hartmann et al., 2002). Curtis et al. (1996) stripped the lower leaves of mountain camellia, which enhanced auxin uptake and increased rooting percentage. Gouveia (1991), however, found wounding to be unnecessary in korean stewartia. Wounding sites can also serve as an easy entry point for pathogens and other harmful microorganisms. To overcome this problem, Dirr and Heuser (1987) suggested a fungicide treatment for propagation of stewartia. Spongberg and Fordham (1975) added $15 \%$ of fungicide thiram to the talc formulation of IBA. In their experiment with japanese stewartia, Struve and Lagrimini (1999) did not find it necessary to treat the cuttings with any fungicide before rooting hormone treatment. Curtis et al. (1996) also did not use any disinfectant for mountain camellia cuttings. In general, stewartias are free of any insect and disease problems.

IBA and $\alpha$-napthaleneacetic acid (NAA) are the most commonly used growth regulators for induction of rooting. Rooting hormones are applied as powders or liquid formulations. Cuttings of korean stewartia (Gouveia, 1991) and mountain camellia (Curtis et al., 1996) can be easily rooted by a quick dip application method. Spongberg and Fordham (1975) reported that IBA, which can be applied as a liquid quick dip or as a talc formulation, was the best rooting stimulant for japanese stewartia.

The concentration of the rooting hormone is also important. The use of auxins should be carried out with caution, as supraoptimal concentrations could reduce overwintering. In many rooted cuttings, higher auxin concentrations used for rooting set a period of dormancy before they were able to resume shoot growth (Goodman and Stimart, 1987). Sun and Bassuk (1993) reported that IBA increased adventitious root formation but also inhibited budbreak in single node 'Royalty' rose (Rosa $\times$ bybrida) cuttings. Because early budbreak and shoot growth are considered important for better overwinter survival, high concentrations of auxin could be detrimental (Sun and Bassuk, 1993).

For stewartia, variable auxin concentrations have been reported to be successful. Fordham (1982) propagated a majority of stewartia species successfully using $0.8 \%\left(8000 \mathrm{mg} \cdot \mathrm{L}^{-1}\right)$ formulation of IBA in talc, with the fungicide thiram added. He also reported a high percentage of rooting, employing a quick dip treatment using a combination of IBA plus NAA at a $2500 \mathrm{mg} \cdot \mathrm{L}^{-1}$ concentration. Haynes (1999) reported high rooting percentages, up to $100 \%$, in semihardwood cuttings of japanese stewartia when treated with $10,000 \mathrm{mg} \cdot \mathrm{L}^{-1}$ potassium salt of IBA (KIBA) solution as quick dip. On the contrary, Struve and Lagrimini (1999) promoted lowering auxin concentrations for rooting of japanese stewartia. They applied an antioxidant (ascorbic acid) and/or a peroxidase inhibitor (caffeic acid) to the base of the cuttings before treating them with a low IBA concentration (100 $\mathrm{mg} \cdot \mathrm{L}^{-1}$ quick dip). They reported that semihardwood cuttings of japanese stewartia taken in August and treated with caffeic acid + IBA or, ascorbic acid + IBA, significantly increased the rooting percentages to $67 \%$ and 64\%, respectively. Curtis et al. (1996) rooted mountain camellia using IBA (quick dip) prepared with $50 \%$ isopropyl alcohol. Their results demonstrated that IBA concentration of 2000 and $4000 \mathrm{mg} \cdot \mathrm{L}^{-1}$ produced $95 \%$ rooting.

The combining of rooting hormones has also been reported to increase overwinter survival in japanese stewartia. Nair et al. (2008) tested four rooting hormone treatments: control, $8000 \mathrm{mg} \cdot \mathrm{L}^{-1} \mathrm{KIBA}$ (quick dip), $8000 \mathrm{mg} \cdot \mathrm{L}^{-1}$ IBA (powder), and a combination of $5000 \mathrm{mg} \cdot \mathrm{L}^{-1}$
KIBA (quick dip) + $3000 \mathrm{mg} \cdot \mathrm{L}^{-1}$ IBA (powder) in japanese stewartia. The percentage of rooted cuttings was significantly lower for control treatment compared with hormone treatments. There were no differences among hormone treatments. However, there were significant differences in the overwinter survival rate among treatments, with the combination treatment exhibiting highest overwinter survival rate $(64.2 \%)$. Thus, it seems that the rooting hormone concentration and the rooting hormone formulation play an important role in overwinter survival.

\section{Rooting medium and fertilization}

The propagation medium should hold the cutting in place, provide adequate moisture, be free of pathogens, permit exchange of air at the base of the cutting, and create a dark or opaque environment. Better rooting is often associated with increased porosity (Gislerod, 1983). In stewartia, a medium composition, perlite + Perennial Mix (Scotts-Sierra, Marysville, $\mathrm{OH}$ ), which provided optimal aeration, ensured higher rooting, minimal rotting, and a better overwinter survival (Nair et al., 2008). It has been demonstrated that stewartia can be rooted in a wide range of rooting medium. Researchers have experimented with a number of medium ingredients and different combinations. Spongberg and Fordham (1975) rooted stewartia in a medium comprising of 1 perlite : 1 sand (by volume). Perkins and Bassuk (1995) successfully rooted japanese stewartia in 1 soil : 2 peat : 1 perlite (by volume) medium. Of all the medium ingredients tested, peat and perlite are the most common ones. Commercial mixes in different combination have also been tested (Nair et al., 2008). Curtis et al. (1996) rooted cuttings of mountain camellia in 1 peat : 3 perlite (by volume) and got $95 \%$ rooting. Gouveia (1991) obtained $80 \%$ rooting rates while propagating korean stewartia in 2 perlite : 1 sand (by volume) medium.

Nitrogen is one of the primary elements needed for proper growth and development in plants. Nitrogen level in the medium not only influences the adventitious rooting but also the shoot growth after rooting (Haissig, 1986). Different levels 
of nitrogen fertilization significantly affected survival percentages and new shoot initiation of sweetgum [ Liquidambar styraciflua (Rieckermann et al., 1999)]. Curtis et al. (1996) rooted softwood cuttings of mountain camellia in three mediums: pine bark, pine bark + dolomitic lime, and pine bark + dolomitic lime + potassium nitrate + Esmigran (minor element additive; Scott Company, Marysville, $\mathrm{OH})+0 \mathrm{~N}-17 \mathrm{P}-0 \mathrm{~K}$ fertilizer. Nitrogen at $0,50,100$, or $200 \mathrm{mg} \cdot \mathrm{L}^{-1}$ was also incorporated. Cuttings rooted in pine bark medium (unamended) and pine bark + dolomitic lime had better overwinter survival rates $(82 \%$ and $83 \%$, respectively) compared with cuttings rooted in pine bark + dolomitic lime + fertilizers (61\% overwinter survival). There was no interaction between medium amendments and $\mathrm{N}$ rate on overwinter survival; however, $\mathrm{N}$ increased shoot growth the following season, especially for the unamended pine bark medium. Fertilizers other than $\mathrm{N}$ have also been tested. Smalley and Avanzato (1992) rooted cuttings of tall stewartia in 1 peat : 2 perlite (by volume) medium amended with different levels of gypsum. They concluded that with the increasing concentration of gypsum there was a reduction in the number of roots and an increase in average root length. However, there was no significant difference in the survival rates among treatments.

\section{Carbohydrate storage and budbreak}

The most widely stated reason for poor establishment and low overwinter survival of some deciduous taxa such as maple, dogwood (Cornus spp.), and numerous others, is the low carbohydrate content in cuttings (Loach and Whalley, 1975; Smalley et al., 1987; Waxman, 1965). The process of rooting consumes sizable amounts of carbohydrates. Loach and Whalley (1975) postulated that the depleted carbohydrate levels can be replenished if the cuttings start to grow before the overwinter period. Only cuttings having sufficient amount of carbohydrates by the end of winter would be able to produce a robust and healthy spring growth that is extremely important for survival (Levitt, 1980; Quinlan, 1969).

The resumption of spring growth in woody plants depends on the carbohydrate reserves accumulated in the previous season (Quinlan, 1969). Overwinter survival of rooted cuttings was greatly enhanced due to increased budbreak and shoot growth brought out by incandescent light + $\mathrm{CO}_{2}$ treatment (Loach and Whalley, 1975). New shoot growth on the rooted cutting contributes toward increased radial growth of the stem (Wilson and Struve, 2004). The added radial growth could lead to the development of a phellogen or endodermis (Clarkson and Robards, 1975), which in turn will be able to protect the underlying vascular tissue and prepare and protect the cutting for winter. Thus, inducing budbeak on rooted cuttings could be an excellent option to enhance the overwinter survival of the cuttings.

Budbreak can be induced through the application of plant growth regulators. Perkins and Bassuk (1995) reported that in japanese stewartia, growth was significantly increased by silver thiosulphate $+\mathrm{GA}_{4 / 7}$ treatment. However, the increased shoot growth was not critical for survival. This means that the carbohydrate reserves, after rooting, were not critically low for cuttings that did not exhibit significant shoot growth. It is believed that carbohydrate reserves are more important than achieving budbreak to insure overwinter survival (Smalley et al., 1987). Perkins and Bassuk (1995) determined that cuttings of japanese stewartia that grew after rooting did not have higher carbohydrate concentrations than those that did not grow.

\section{Cold acclimation and overwinter storage temperature}

Preparation for the onset of low temperature is an important factor in the growth and survival of woody plants (Grace, 1987). In nature, the living bark of many woody plant species acclimates to cold in two stages during the autumn: cold acclimation and freeze tolerance (Irving and Lanphear, 1967). After rooting japanese stewartia cuttings under extended daylength, Haynes (1999) acclimated the cuttings under three conditions: decreasing daylength and temperature (outside), decreasing daylength and constant temperature (greenhouse), or constant extended daylength (greenhouse). She reported no effect of acclimation treatments on cutting survival, budbreak, or stem elongation; however, at the time of final evaluation, all the cuttings were dead. Even though there were no prominent effects of acclimation observed, it would be important to gradually acclimate the cuttings in the fall to lower temperatures before storage.

The temperature and duration of storage are important factors influencing the overwinter survival of cuttings. Stewartia usually survives and grows when overwintered at $1{ }^{\circ} \mathrm{C}$ for 3 to 4 months (Fordham, 1982). For japanese stewartia, an overwintering temperature of $5{ }^{\circ} \mathrm{C}$ has been recommended to provide a satisfactory chilling requirement and overwinter survival rate (Nair et al., 2008). Curtis et al. (1996) studied the effect of overwintering storage duration on overwinter survival of mountain camellia rooted cuttings. The best overwinter survival was recorded at $6^{\circ} \mathrm{C}$ and a chilling duration of 10 weeks. Budbreak and shoot growth were positively related to the weeks of chilling. This result indicates that chilling temperature and chilling duration are important for overwinter survival and continued postoverwinter growth of mountain camellia.

In tall stewartia, bark splitting was observed in cuttings that failed to overwinter successfully (Smalley and Lindstrom, 1991). Poor overwinter survival in difficult-to-overwinter species cannot be attributed to a single factor and it varies among species. For example, in japanese stewartia, the chilling temperature requirement could be one of the important factors needed for successful overwinter survival, while it was found that for witchhazel, carbohydrate reserves played a more critical role (Perkins and Bassuk, 1995). In our preliminary studies, most of the cuttings did put forth new flush in the spring but ultimately withered off. Cuttings of stewartia that did not overwinter showed foliar necrosis and stem decay near the base close to the medium (A. Nair and D. Zhang, unpublished data). The taxa, whose stems have high phenolic content such as stewartia, may exhibit decaying symptoms (browning) in their roots. Further experiments conducted in our laboratory targeted 
specific aspects like rooting hormone, rooting medium, and overwintering temperature and reported satisfactory results (Nair et al., 2008).

\section{Micropropagation}

Some of the issues related to sexual and asexual propagation techniques that impede stewartia propagation are low seed viability, seedling variability, and poor overwinter survival. Therefore, micropropagation appears to be an ideal choice for circumventing the abovementioned problems related to conventional propagation techniques. A large number of plants could be generated and plants generated are true to type.

McGuigan et al. (1997) cultured single node explants of japanese stewartia on an agar-solidified woody plant medium (WPM) amended with two growth regulators: $\mathrm{N}$-(3-methyl2-butenyl)- $1 \mathrm{H}$-purin-6-amine (2iP) or N-phenyl-N-1, 2, 3-thiadiazol-5ylurea (TDZ) at different concentrations. Explants taken at the softwood stage had less contamination and greater budbreak than explants taken from more mature stem tissue. Shoot elongation was also highest in explants taken from softwood stock plant. It was notable that budbreak was highest for explants cultured on WPM on $48.2 \mu_{\mathrm{M}} 2 \mathrm{iP}$. Explants cultured on medium containing TDZ as the growth regulator exhibited reduced budbreak, less vigorous growth, and appeared stunted. Effect of the position of the explant (axillary node position) did not influence budbreak frequency or shoot elongation. McGuigan et al. (1997) also reported no significant effect of axillary node position and incorporation of $\mathrm{GA}_{3}$ on budbreak or shoot elongation.

Although japanese stewartia was propagated successfully by micropropagation, large numbers of plantlets were not achieved because explants produced only one microcutting per nodal segment (McGuigan et al., 1997). A factor that needs to be addressed is the possibility of interference due to polyphenolic compounds, as plants belonging to Theaceae family are known to possess high concentration of polyphenols. Thus, before the micropropagation protocol is applicable to a commercial situation, more studies need to be undertaken to resolve the outstanding issues related to micropropagation.

\section{Conclusion}

Many of the studies available in the literature were conducted to tackle a specific propagation aspect of stewartia. Each study investigated a particular aspect of propagation such as medium composition, rooting hormone, etc. and provided pieces of information that could be used to solve the bigger puzzle of overwinter survival. An outcome of those studies was a better understanding of the overall processes that govern or influence the overwintering process in stewartia. It is evident that overwinter survival of stewartia is controlled by a number of factors and that if optimum conditions are provided, stewartia can be propagated. Ironically, even after two decades of research initiatives, propagation of stewartia is still considered to be a challenge and lacks a clear, definite solution.

The important fact to recognize at this point is that the overwinter success rates reported in most of the studies are lower than the industry standards. A higher rate of overwinter survival is needed for an economically viable propagation program. Even with the current information on stewartia, there are not many greenhouses or nurseries that are actively pursuing stewartia propagation. This could be due to difficulties associated with propagation or lack of consumer demand. Of the numerous research projects undertaken to mitigate propagation difficulties in stewartia, the aspect of overwinter survival is the most critical and needs further attention. In addition, to get a better understanding of issues pertaining to stewartia, we suggest an extensive survey of various nursery and greenhouse growers who are involved in stewartia propagation/production. To determine impediments that hinder market availability of stewartia, feedback obtained from growers and industry personnel would help researchers correctly determine the core problem and formulate strategies and conduct studies to address them. No matter how easy or difficult it is to propagate, industry feedback and cooperation is imperative to the availability and popularization of any woody plant species. The landscape industry always has a steady demand for new plants and cultivars, and a better understanding of reasons behind the absence of stewartia in horticulture trade will benefit consumers and the industry. Stewartias certainly exhibit traits and features that are desirable in our landscapes.

\section{Literature cited}

Clarkson, D.T. and A.W. Robards. 1975. The endodermis, its structural development and physiological role, p. 415-436. In: J.G. Torrey and D.T. Clarkson (eds.). The development and function of roots. Academic Press, London.

Curtis, D.L., T.G. Ranney, F.A. Blazich, and E.P. Whitman. 1996. Rooting and subsequent overwinter survival of stem cuttings of Stewartia ovata. J. Environ. Hort. 14:163-166.

DeWolf, G.P. 1969. The introduction of our hardy stewartias. Arnoldia 29:41-48.

Dirr, M.A. 1998. Manual of woody landscape plants: Their identification, ornamental characteristics, culture, propagation and uses, 5th ed. Stipes, Champaign, IL.

Dirr, M.A. and A.E. Richards. 1989. Cutting propagation of Hamamelis $\times$ intermedia 'Arnold Promise'. Plant Propagator 1:9-10.

Dirr, M.A. and C.W. Heuser. 1987. The reference manual of woody plant propagation. Varsity Press, Athens, GA.

Donnelly, J.R. and H.W. Yawney. 1972. Some factors associated with vegetatively propagating sugar maple by stem cuttings. Proc. Intl. Plant Prop. Soc. 22: 423-430.

Drew, J.J., M.A. Dirr, and A.M. Armitage. 1993. Effects of fertilizer and night interruption on overwinter survival of rooted cuttings of Quercus L. J. Environ. Hort. 11:97-101.

Ekstrom, D.E. and J.A. Ekstrom. 1988. Propagation of cultivars of Stewartia, Acer palmatum and Fagus sylvatica for open ground production. Proc. Intl. Plant Prop. Soc. 38:180-184.

Flemer, W. 1982. Propagating shade trees by cuttings and grafts. Proc. Intl. Plant Prop. Soc. 32:569-579.

Fordham, A.J. 1982. Stewartia: Propagation data for ten taxa. Proc. Intl. Plant Prop. Soc. 32:476-481.

Gislerod, H.R. 1983. Physical conditions of propagation media and their influence of the rooting of cuttings. III. The effects of air content and temperature in different propagation media on the rooting of cutting. Plant Soil 75:1-14.

Goodman, M.A. and D.P. Stimart. 1987. Factors regulating overwinter survival of 
newly propagated stem tip cuttings of Acer palmatum Thunb. 'Bloodgood' and Cornus florida L. var. rubra. HortScience 22:1296-1298.

Gouveia, R.J. 1991. Stewartia koreana. Amer. Nurse 174:74.

Grace, J. 1987. Climatic tolerance and distribution of plants. New Phytol. 106: 113-130.

Haissig, B.E. 1986. Metabolic processes in adventitious rooting of cuttings, p. 14l190. In: M.B. Jackson (ed.). New root formation in plants and cuttings. Martinus Nijhoff, Dordrecht, The Netherlands.

Halward, R.R. 1966. Propagation of difficult, unusual and rare plants. Proc. Intl. Plant Prop. Soc. 43:445-449.

Hartmann, H.T., D.E. Kester, F.T. Davies, Jr., and R.T. Geneve. 2002. Plant propagation: Principles and practices, 6th ed. Prentice Hall, Upper Saddle River, NJ.

Haynes, J.G. 1999. Improving vegetative propagation techniques and establishment practices for Stewartia koreana Nakai ex Rehder, Stewartia pseudocamellia Maxim. and Cornus Canadensis L. MS Thesis, Dept. Plant Soil Environ. Sci., Univ. Maine, Orono.

Hohn, T. 1994. Stewartia: A recommendation for a tree that seems to have it all: Outstanding flowers, foliage and bark. Amer. Nursery 180:42-49.

Irving, R.M. and F.O. Lanphear. 1967. Environmental control of cold hardiness in woody plants. Plant Physiol. 42:11911196.

Levitt, J. 1980. Responses of plants to environmental stresses. Academic Press, New York.

Li, J. 1996. A systematic study on the genus Stewartia and Hartia (Theaceae). Acta Phytotaxonomica Sinica 34:48-67.

Loach, K. and D.N. Whalley. 1975. Use of light, carbon dioxide enrichment and growth regulators in the overwintering of hardy ornamental nursery stock cuttings. Acta Hort. 54:105-115.

Macdonald, B. 1974. Discussion group report camellia propagation. Proc. Intl. Plant Prop. Soc. 24:152-154.

McGuigan, P.J., F.A. Blazich, and T.G. Ranney. 1997. Micropropagation of Stewartia pseudocamellia. J. Environ. Hort. 15:65-68.

Nair, A. 2006. Production of Stewartia pseudocamellia Maxim. MS Thesis, Dept. Plant Soil Environ. Sci., Univ. Maine, Orono.

Nair, A., D. Zhang, J. Smagula, and D. Hu. 2008. Rooting and overwintering stem cuttings of Stewartia pseudocamellia Maxim. Relevant to hormone, media and temperature. HortScience 43:2124-2128.

Oleksak, B.A. and D.K. Struve. 1999. Germination of Stewartia pseudocamellia seeds is promoted by desiccation avoidance, gibberellic acid treatment and warm and cold stratification. J. Environ. Hort. $17: 44-46$.

Perkins, A. and N. Bassuk. 1995. The effect of growth regulators and overwinter survival of rooted cuttings. Proc. Intl. Plant Prop. Soc. 45:450-458.

Quinlan, J.D. 1969. Mobilization of ${ }^{14} \mathrm{C}$ in the spring following the autumn assimilation of ${ }^{14} \mathrm{CO}_{2}$ by an apple rootstock. J. Hort. Sci. 44:107-110.

Rieckermann, H., B. Goldfarb, M. Cunningham, and R.C. Kellison. 1999. Influence of nitrogen, photoperiod, cutting type, and clone on root and shoot development of rooted stem cuttings of sweetgum. New For. 18:231-244.

Smalley, T.J. and D. Avanzato. 1992. Rooting and survival of Stewartia monadelpha cuttings in gypsum-amended rooting media. Proc. Southern Nursery Assn. 37:267-268.

Smalley, T.J. and M.A. Dirr. 1986. The overwinter survival problems of rooted cuttings. Plant Propagator 32:10-14.
Smalley, T.J. and O.M. Lindstrom. 1991. Effect of benzyladenine and myo-inositol on cold hardiness and overwinter survival of Stewartia monadelpha cuttings. Proc. Southern Nursery Assn. 36:248-251.

Smalley, T.J., M.A. Dirr, and G.G. Dull. 1987. Effect of extended photoperiod on budbreak, overwinter survival and carbohydrate levels of Acer rubrum 'October Glory' rooted cuttings. J. Amer. Soc. Hort. Sci. 112:459-463.

Spongberg, S.A. and A.J. Fordham. 1975. Stewartias: Small trees and shrubs for all seasons. Arnoldia 35:165-180.

Struve, D.K. and M. Lagrimini. 1999. Survival and growth of Stewartia pseudocamellia rooted cuttings and seedlings. J. Environ. Hort. 17:53-56.

Struve, D.K., B.A. Olesak, T. Kawahara, and A. Kanazashi. 1999. Germination of japanese stewartia seeds: The effects of warm and cold stratification. J. Environ. Hort. 17:197-202.

Sun, W.Q. and N.L. Bassuk. 1993. Auxin induced ethylene synthesis during rooting and inhibition of budbreak of 'Royalty' rose cuttings. J. Amer. Soc. Hort. Sci. 118:638-643.

Waxman, S. 1965. Photoperiodic treatment and its influence on rooting and survival of cuttings, "lighting under mist". Proc. Intl. Plant Prop. Soc. 15: 94-97.

Wells, J.S. 1962. Wounding cuttings as a commercial practice. Proc. Intl. Plant Prop. Soc. 12:47-55.

Wilson, P.J. and D.K. Struve. 2004. Overwinter mortality in stem cuttings. J. Hort. Sci. Biotechnol. 79:842-849.

Yang, S.X. 1997. A preliminary revision of Pyrenaria from China and its adjacent regions. Chin. J. Appl. Environ. Biol. 3:276-288. 